\title{
Translation and Validation of Enhanced Asian Rome III Questionnaires in Bengali Language for Diagnosis of Functional Gastrointestinal Disorders
}

\author{
M Masudur Rahman, ${ }^{1}$ Uday C Ghoshal, ${ }^{2 *}$ A H M Rowshon, ${ }^{3}$ Faruque Ahmed, ${ }^{1}$ Md Golam Kibria, ${ }^{1}$ Mahmud Hasan, ${ }^{4}$ Kok-Ann Gwee, ${ }^{5}$ \\ and William E Whitehead ${ }^{6}$
}

${ }^{\prime}$ Dhaka Medical College, Dhaka, Bangladesh; ${ }^{2}$ Department of Gastroenterology, Sanjay Gandhi Postgraduate Institute of Medical Sciences, Lucknow, India; ${ }^{3}$ Shaheed Suhrawardy Medical College Hospital, Dhaka, Bangladesh; ${ }^{4}$ Bangladesh Medical Research Council, Dhaka, Bangladesh; ${ }^{5}$ Department of Medicine, Yong Loo Lin School of Medicine, National University of Singapore, Singapore; and ${ }^{6}$ Center for Functional GI and Motility Disorders, University of North Carolina at Chapel Hill, NC, USA

\section{Background/Aims}

Functional gastrointestinal disorders (FGIDs), diagnosed by symptom-based criteria due to lack of biomarkers, need translatedvalidated questionnaires in different languages. As Bengali, the mother tongue of Bangladesh and eastern India, is the seventh most spoken language in the world, we translated and validated the Enhanced Asian Rome III questionnaire (EAR3Q) in this language.

\section{Methods}

The EAR3Q was translated in Bengali as per guideline from the Rome Foundation. The translated questionnaire was validated prospectively on Bengali-speaking healthy subjects $(H S, n=30)$, and patients with functional dyspepsia ( $F D, n=35)$, irritable bowel syndrome (IBS, $n=40)$ and functional constipation ( $F C, n=12)$ diagnosed by clinicians using the Rome III criteria. The subjects were asked to fill-in the questionnaire again after 2 weeks, to check for its reproducibility.

\section{Results}

During translation, the original and the backward translated English versions of the questionnaire demonstrated high concordance. Sensitivity of the Bengali questionnaire to diagnose patients with $\mathrm{FD}, \mathrm{IBS}, \mathrm{FC}$, and $\mathrm{HS}$ was $100 \%, 100 \%, 75 \%$, and $100 \%$, respectively, considering diagnosis by the clinicians as the gold standard. On test-retest reliability analysis, Kappa values for FD, IBS, FC, and HS were 1.0, 1.0, 0.83, and 1.0, respectively. The Bengali questionnaire detected considerable overlap of FD symptoms among patients with IBS, IBS among patients with FD, and FD among patients with $F C$, which were not detected by the clinicians.

\section{Conclusions}

We successfully translated and validated the EAR3Q in Bengali. We believe that this translated questionnaire will be useful for clinical evaluation and research on FGIDs in the Bengali-speaking population.

(J Neurogastroenterol Motil 2016;22:240-247)

Key Words

Bangladesh; Constipation; Dyspepsia; India; Irritable bowel syndrome

Received: August 13, 2015 Revised: November 22, 2015 Accepted: November 29, 2015

(c) This is an Open Access article distributed under the terms of the Creative Commons Attribution Non-Commercial License (http://creativecommons. org/licenses/by-nc/4.0) which permits unrestricted non-commercial use, distribution, and reproduction in any medium, provided the original work is properly cited.

${ }^{*}$ Correspondence: Uday C Ghoshal, MD, DNB, DM, FACG, RFF

Department of Gastroenterology, Sanjay Gandhi Post Graduate Institute of Medical Sciences, Lucknow-226014, India Tel: +91-800-4904780, Fax: +91-522-2668017 or 2668078, E-mail: udayghoshal@gmail.com 


\section{Introduction}

Functional gastrointestinal disorders (FGIDs) are common conditions in gastroenterology practice and are diagnosed currently by a combination of multiple symptoms, absence of alarm features, and organic causes explaining the symptoms on routine investigations. ${ }^{1}$ Though extensive investigations may reveal several conditions such as gut dysbiosis, celiac disease, lactose malabsorption, food hypersensitivity, tropical sprue, or fecal evacuation disorders explaining symptoms in a subset of patients with FGIDs, the current Rome III diagnostic algorithm does not warrant such testing to exclude these causes before making a diagnosis of FGID. To bring homogeneity in research, to avoid excessive investigations complicating management of these patients in resource limited settings, and to be useful in clinical practice, the Rome Foundation developed the Rome criteria ${ }^{2-4}$ for classifications and diagnosis of FGIDs by consensus, which is currently in its third iteration. ${ }^{4}$

Although the Rome criteria are widely used in research and patient care, ${ }^{5,6}$ these have limitations as these were originally developed in English-speaking Western populations, and may not give sufficient importance to the socio-cultural issues, language, symptom perception, and reporting and spectrum of FGIDs in non-Western populations. ${ }^{7}$ Socio-cultural factors influence the illness beliefs, perception, and expression of gastrointestinal (GI) symptoms. ${ }^{8-11}$ Therefore, for symptom-based diagnosis, linguistic translation of a questionnaire alone is quite inadequate unless cultural adaptation of the terminology is undertaken to imply the underlying intentions. Since FGIDs are diagnosed by symptoms-based criteria, ${ }^{1,12}$ and symptoms are influenced by psychosocial and socio-cultural factors, ${ }^{8-11}$ there has been concern whether the Rome III questionnaire in its original form would be similarly applicable for uniform diagnosis, sub-typing, and treatment allocation for FGIDs throughout the world. ${ }^{11,13}$ To overcome some of the above-mentioned limitations, the Enhanced Asian Rome III questionnaire (EAR3Q) ${ }^{14}$ has been developed by the Asian experts by consensus, which is a culturally adapted version of the Rome III diagnostic questionnaire (R3DQ). ${ }^{15}$

Bengali is one of the most spoken languages and is ranked seventh in the world. ${ }^{16}$ It is the second most commonly spoken language in India and a native language to the region of Eastern South Asia formally known as Bengal, which comprises the present day Bangladesh, the Indian state of West Bengal, and parts of the Indian states of Tripura and Assam. ${ }^{17}$ Population based studies on FGIDs, done in a Bengali speaking population ${ }^{18-20}$ suggest that the epidemiological features of FGIDs in this region are comparable to most Asian studies and may differ from the West. ${ }^{7,18-28}$ However, these findings need to be addressed further in multi-national crosscultural studies. ${ }^{10,11}$ One of the barriers to such studies is the lack of a culturally adapted questionnaire that has been translated and validated in Bengali. Therefore, as an initial step towards such studies, we aimed to translate the EAR3Q into Bengali and to validate it in prospective samples of healthy subjects (HS), patients suffering from functional dyspepsia (FD), irritable bowel syndrome (IBS), and functional constipation (FC) to see whether the translated questionnaire can diagnose different FGIDs according to the Rome criteria.

\section{Materials and Methods}

The EAR3Q was translated in Bengali first. The translated questionnaire was tested for understandability among a group of HS. It was then validated in prospective samples of Bengalispeaking patients suffering from FD, IBS, and FC diagnosed by the clinicians as would be done in practice and on another group of HS twice at 2-week intervals.

\section{The Process of Translation}

During a 9-month period (between May, 2011 and February, 2012) the EAR3Q was translated as per guideline from the Rome Foundation. ${ }^{29}$ The EAR3Q was translated into Bengali by 2 independent translators, one of them was a gastroenterologist and the other an internal medicine specialist. Both were bi-lingual physicians, native Bengali speakers, and were fluent in English. The product of this step was forward version 1a and $1 \mathrm{~b}$ in Bengali (Figure). In the next step, the two versions were reconciled into a final Bengali version (version 2) by a gastroenterologist who was well-conversant in Bengali and English. In the next step, an English teacher, who was well-conversant in Bengali and English, back translated this reconciled Bengali questionnaire into English. Subsequently, the original and backward translated English versions of the questionnaire were assessed for similarities of language and interpretation. During this phase, revision and modification of Bengali version 2 was made as needed to create Bengali version 3. The changes made during this phase were recorded.

\section{Cognitive Debriefing}

Cognitive debriefing was done by testing the questionnaire among 10 Bengali speaking subjects with apparently normal health and patients with different GI symptoms. To assess the clarity of 


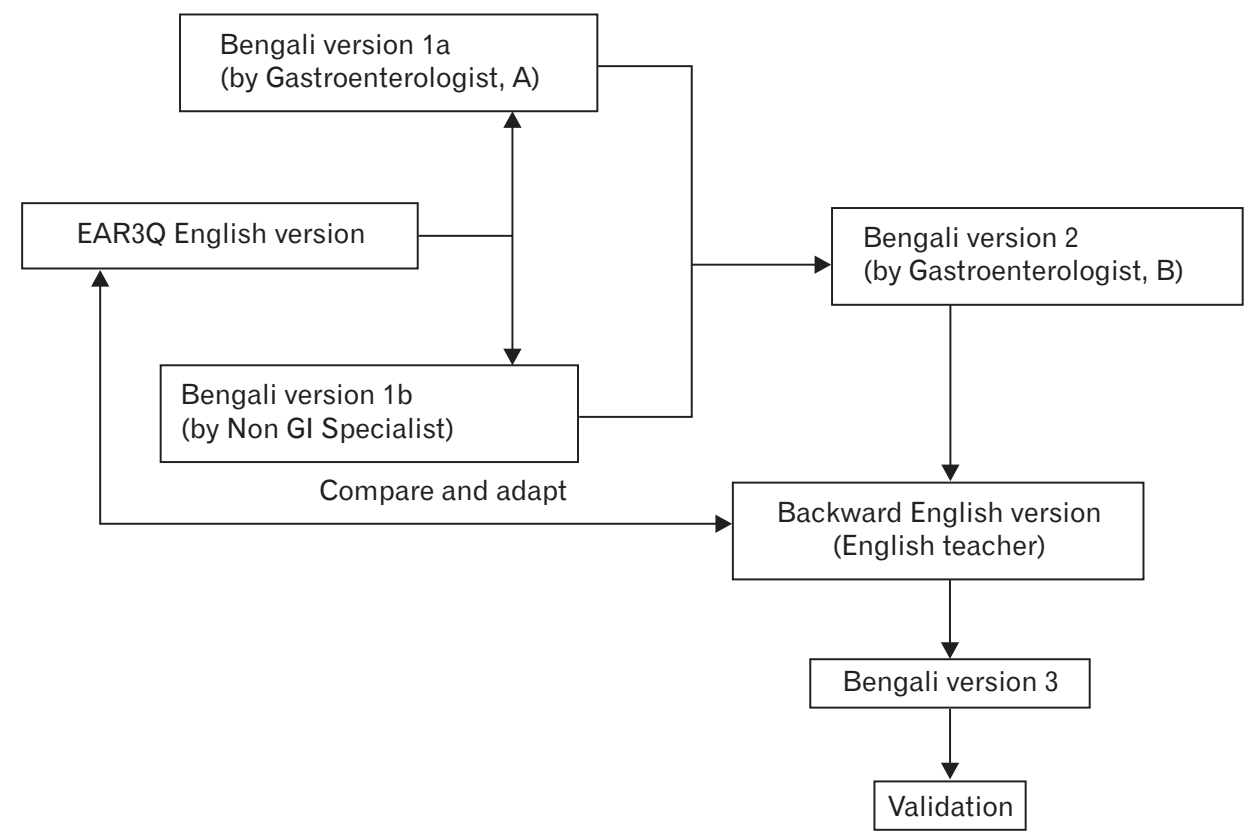

Figure. Outline of the process of translation validation of the Enhanced Asian Rome III questionnaire (EAR3Q) in Bengali language. GI, gastrointestinal. individual questions, a 10-point Likert scale was used; value of 1 in the Likert scale indicated poor understandability and that of 10 suggested complete understandability.

\section{Validation of the Translated Questionnaire}

The final translated questionnaire (Supplementary Table) was validated on subjects with FD, IBS, FC, and HS. Patients with FD, IBS, and FC were diagnosed by the clinicians as would be done in practice using the Rome III criteria by clinical interview. During enrollment, every subject was asked about presence of alarm features. Those with alarm features were adequately investigated by colonoscopy, imaging, and laboratory studies as indicated, to exclude organic diseases before inclusion into the study. Those without alarm features, however, were also investigated with routine laboratory tests including upper GI endoscopy, colonoscopy, and imaging.

The HS were apparently healthy with no significant medical history. After the clinicians made the categorical diagnosis of FGID in the clinic, the patients and the HS were requested to fill in the questionnaire by themselves. A research assistant sat with the subjects while they filled in the questionnaire for any clarification, if needed, and for recording the time needed to fill up the questionnaire. The research assistant was a post-graduate trainee in gastroenterology. She was trained on FGIDs, specifically the EAR3Q. She is a native speaker of Bengali. She was involved throughout the study. After an interval of 2 weeks, the subjects were asked to fill in the questionnaire again. The protocol was approved by the Ethics and Review Committee of Shaheed Suhrawardy Medical College and Hospital, and informed consent was obtained from each subject.

\section{Statistical Methods}

The categorical and continuous data are presented as proportion, median, and range, respectively. Considering the diagnosis by the clinician as the gold standard, the sensitivity of the questionnaire to pick-up the correct diagnostic category at the initial visit was assessed. Specificity was calculated by estimating the proportion of HS considered as healthy according to the response from the questionnaire. The agreement between the diagnoses made at 2 time points using the questionnaire was evaluated using kappa statistics. Values for kappa $>0.80$ were considered excellent agreement, between $0.61-0.80$ as good agreement, and those below $<0.6$ as poor agreement.

\section{Results}

\section{Demographic Characteristics of the Participants}

The final translated questionnaire was validated on 117 subjects (40 patients with IBS, $35 \mathrm{FD}, 12 \mathrm{FC}$, and $30 \mathrm{HS}$ ) by clinical diagnosis. The age of the HS and patients with IBS enrolled in the study were lower compared to patients with $\mathrm{FD}$ and $\mathrm{FC}$, and the 
gender was comparable except between FD and IBS (Table 1). None of the enrolled patients was illiterate (educational status presented in Table 1). Monthly family income of the subjects with different FGIDs and HS as categorized as per Kuppuswamy's classification $^{30}$ is shown in Table 1. Most of the subjects' occupation was in the service sector (Table 1).

\section{Cognitive Debriefing}

During the cognitive debriefing and validation study, all the subjects reported that the questionnaire was easily understood. However, most of them complained that it was too long. The median time needed to complete the questionnaire was 25 minutes (range, 15-45 minutes). In the 10-point Likert scale, the questions were scored satisfactory (score ranging from 5-10, mode 10).

\section{Validity and Reliability}

The sensitivity and specificity of the questionnaire to detect the clinical diagnosis made by the physician based on the Rome III criteria were very high. The sensitivity of the questionnaire to diagnose IBS, FD, and $\mathrm{HS}$ at the initial visit and at the second visit after an interval of 2 weeks was $100 \%$, whereas for FC it was $75 \%$ at the initial visit and $83 \%$ at the second visit. The specificity of the questionnaire to diagnose HS as healthy was $100 \%$ (Table 2). On testretest reliability, the questionnaire was found to be highly reliable. Though there was complete agreement between the initial diagnosis and that at the second visit for IBS, FD, and HS, this was not so for FC (Table 3).

Table 1. Demographic and Clinical Parameters of Patients and Healthy Subjects Included in the Translation-validation Study

\begin{tabular}{|c|c|c|c|c|c|}
\hline Parameters & HS & IBS & $\mathrm{FD}$ & $\mathrm{FC}$ & $P$-value \\
\hline Number of subjects & 30 & 40 & 35 & 12 & \\
\hline Age (median age [range], yr) & $29(18-46)$ & $28(18-65)$ & $30(18-70)$ & $36(18-70)$ & NS \\
\hline Gender (male) & $23(76.6 \%)$ & $36(90.0 \%)$ & $22(62.8 \%)$ & $10(83.3 \%)$ & NS for all except FD vs IBS \\
\hline \multicolumn{6}{|l|}{ Education } \\
\hline Class I to X & $1(3.3 \%)$ & $12(30.0 \%)$ & $20(57.2 \%)$ & $5(41.7 \%)$ & \\
\hline $\mathrm{SSC} / \mathrm{HSC}$ & $5(16.7 \%)$ & $13(32.5 \%)$ & $8(22.8 \%)$ & $5(41.7 \%)$ & $<0.001$ \\
\hline Graduate/postgraduate & $19(63.3 \%)$ & $13(32.5 \%)$ & $7(20.0 \%)$ & $2(16.7 \%)$ & \\
\hline Professionals/others & $5(16.7 \%)$ & $2(5.0 \%)$ & $0(0.0 \%)$ & $0(0.0 \%)$ & \\
\hline \multicolumn{6}{|l|}{ Occupation } \\
\hline Housewife & $2(6.7 \%)$ & $4(10.0 \%)$ & $9(25.71 \%)$ & $2(16.7 \%)$ & \\
\hline Service sector & $24(80.0 \%)$ & $12(30.0 \%)$ & $16(45.7 \%)$ & $7(58.3 \%)$ & 0.001 \\
\hline Business & $0(0.0 \%)$ & $7(17.5 \%)$ & $3(8.6 \%)$ & $0(0.0 \%)$ & \\
\hline Others & $4(13.3 \%)$ & $17(42.5 \%)$ & $7(20.0 \%)$ & $3(25.0 \%)$ & \\
\hline \multicolumn{6}{|c|}{ KS family income group (taka per month) } \\
\hline$>22500($ KS group 1,2$)$ & $14(46.7 \%)$ & $6(15.0 \%)$ & $1(2.9 \%)$ & $3(25.0 \%)$ & \\
\hline 22499-11236 (KS group 3, 4) & $9(30.0 \%)$ & $16(40.0 \%)$ & $21(60.0 \%)$ & $3(25.0 \%)$ & $<0.001$ \\
\hline$<11235$ (KS group 5-7) & $7(23.3 \%)$ & $18(45.0 \%)$ & $13(37.1 \%)$ & $6(50.0 \%)$ & \\
\hline
\end{tabular}

HS, healthy subjects; IBS, irritable bowel syndrome; FD, functional dyspepsia; FC, functional constipation; NS, not significant; SSC, secondary school certificate; HSC, higher school certificate; KS, Kuppuswamy's.

1 US dollar $=80$ taka in October 2015 .

Table 2. Diagnostic Performance, Sensitivity, and Specificity of Bengali Version of Enhanced Asian Rome III Questionnaires

\begin{tabular}{lccc}
\hline $\begin{array}{c}\text { Diagnostic category } \\
\text { (healthy vs FBDs) }\end{array}$ & $\begin{array}{c}\text { Concordance between clinical and } \\
\text { questionnaire-based diagnosis on initial visit }\end{array}$ & Sensitivity & Specificity \\
\hline Healthy control $(\mathrm{n}=30)$ & 30 & $100 \%$ & $100 \%$ \\
IBS $(\mathrm{n}=40)$ & 40 & $100 \%$ & $100 \%$ \\
FD $(\mathrm{n}=35)$ & 35 & $75 \%$ & $100 \%$ \\
FC $(\mathrm{n}=12)$ & 9 & $100 \%$ \\
\hline
\end{tabular}

FBDs, functional bowel diseases; IBS, irritable bowel syndrome; FD, functional dyspepsia; FC, functional constipation. 
Table 3. Diagnostic Performance, Test-retest Reliability of Bengali Version of Enhanced Asian Rome III Questionnaires

\begin{tabular}{lccc}
$\begin{array}{c}\text { Diagnostic category } \\
\text { (healthy vs FBDs) }\end{array}$ & $\begin{array}{c}\text { Concordance between clinical and } \\
\text { questionnaire-based diagnosis } \\
\text { on initial visit }\end{array}$ & $\begin{array}{c}\text { Concordance between clinical and } \\
\text { questionnaire-based diagnosis } \\
\text { on 14th day visit }\end{array}$ & $\begin{array}{c}\text { Kappa values (EAR3Q based } \\
\text { diagnosis at initial and } \\
\text { 2-week follow-up) }\end{array}$ \\
\hline Healthy control $(\mathrm{n}=30)$ & 30 & 30 & 1.00 \\
IBS $(\mathrm{n}=40)$ & 40 & 40 & 1.00 \\
FD $(\mathrm{n}=35)$ & 35 & 35 & 1.00 \\
FC $(\mathrm{n}=12)$ & 9 & 10 & 0.83 \\
\hline
\end{tabular}

FBDs, functional bowel diseases; EAR3Q, Enhanced Asian Rome III questionnaire; IBS, irritable bowel syndrome; FD, functional dyspepsia; FC, functional constipation.

Table 4. Overlap Between Different Functional Bowel Diseases Detected by Bengali Version of Enhanced Asian Rome III Questionnaires During Validation Study

\begin{tabular}{|c|c|c|c|c|}
\hline \multirow{2}{*}{ Diagnostic category } & \multicolumn{2}{|c|}{ First visit } & \multicolumn{2}{|c|}{ Second visit at 2 weeks } \\
\hline & Concomitant FBD (overlap) & $\mathrm{n}(\%)$ & Concomitant FBD (overlap) & $\mathrm{n}(\%)$ \\
\hline $\operatorname{IBS}(\mathrm{n}=40)$ & FD & $12(30.0 \%)$ & FD & $12(30.0 \%)$ \\
\hline \multirow[t]{2}{*}{$\mathrm{FD}(\mathrm{n}=35)$} & IBS & $8(22.8 \%)$ & IBS & $10(28.5 \%)$ \\
\hline & $\mathrm{FC}$ & $3(8.5 \%)$ & $\mathrm{FC}$ & $1(2.9 \%)$ \\
\hline $\mathrm{FC}(\mathrm{n}=12)$ & FD & $1(11.1 \%)$ & FD & $2(20.0 \%)$ \\
\hline
\end{tabular}

FBD, functional bowel disease; IBS, irritable bowel syndrome; FD, functional dyspepsia; FC, functional constipation.

\section{Overlap}

The questionnaire detected considerable overlap between IBS with FD, FD with IBS or FC, FC with FD, both at the initial and follow-up visits, which was overlooked by the clinicians. About 20 $30 \%$ of patients with IBS had FD or FD patients had either IBS or FC. Frequency of overlap between IBS, FD, and FC are shown in Table 4.

\section{Discussion}

In this study, EAR3Q, ${ }^{14}$ developed by a group of Asian experts with an aim to overcome some of the linguistic and cultural limitations of the original Rome questionnaire to diagnose FGIDs in Asia has been translated and validated in Bengali as per guideline by the Rome Foundation. ${ }^{29}$ The questionnaire was easily understood by the volunteers, had high sensitivity and specificity to diagnose various FGIDs, and had excellent test-retest reliability.

In EAR3Q, though all the original R3DQ questionnaires were retained, some culturally adapted questions were added after the original Rome III questions for which understanding by Asian patients was thought to be difficult. Moreover, new questions have been developed for symptoms where it was considered that existing questions were inadequate for describing Asian patients' and clini- cians' perspective. In the earlier study, though the Hindi, Telugu, and Thai questionnaires were quite sensitive and specific, the Korean and Indonesian questionnaires were not. ${ }^{14}$ The current study showed that the Bengali questionnaire was highly sensitive and specific to diagnose FGIDs. In Bengali language the term abdominal fullness, distension, and discomfort carry very close meanings and it is very difficult to distinguish between these terms in Bengali. Certain terms such as retching, bloating, incontinence, flatulence, mushy stool, anal blockage, and digital maneuver were difficult to translate into Bengali as popular and widely used terms for these words were difficult to find out.

One of the striking features of our study is that the Bengali questionnaire detected considerable overlap between various categories of FGIDs. Such overlap has also been found in Hindi, Telugu, Chinese, and Korean validation studies. ${ }^{14}$ There are several possible reasons for this. Firstly, overlaps between various FGIDs are common in the Asian community. ${ }^{20,31,32}$ Secondly, in clinical practice the physician may focus on predominant symptoms and may not inquire into all the symptoms of FGIDs. For example, physicians may focus on upper GI symptoms once they diagnose FD and may not routinely inquire about bowel habits. Thirdly, as patients with overlap of both upper and lower GI symptoms are not categorized as a distinct disorder by the current classification of FGIDs, physicians may not direct adequate attention to recognize such conditions 
in their busy clinics. This may result in inadequate treatment, incomplete improvement, and dissatisfaction of the patients. This has also been found in our earlier validation study. ${ }^{14}$

Overlap between FD and IBS has been reported to be common in Asia. ${ }^{20,31,32}$ In a recent community-based survey among 3000 Bengali speaking rural and urban population selected by cluster sampling in a district of Bangladesh, $42 \%$ of FD subjects had IBS and $27 \%$ IBS subjects had FD. ${ }^{20}$ In a multivariate logistic regression analysis, early satiety and epigastric pain were found to be the independent risk factors for FD-IBS overlap. ${ }^{20}$ In a study from Taiwan, among the patients diagnosed as FD after upper GI endoscopy, half were found to have IBS on detailed questioning. ${ }^{32}$

As upper GI symptoms are common among IBS patients in Asia, patients may be diagnosed as FD and the associated IBS symptoms might be overlooked. ${ }^{7,33}$ Two rural and urban population-based studies in Bangladesh using the Rome I and Rome II criteria demonstrated that more than $50 \%$ patients with IBS had upper abdominal symptoms. ${ }^{18,19}$ Similarly, in a pan-Indian study, $49 \%$ of IBS subjects had epigastric pain. ${ }^{34}$ For psychosocial and socio-cultural reasons, patients may be more concerned about upper GI symptoms rather than their bowel habits in Asia.

The translated questionnaire failed to pick-up diagnosis made by the physicians in a proportion of patients. This may result, as stated in other validation studies in Asia, ${ }^{14}$ from the discrepancy of perception about constipation by the physician and the patients. The patients often mean constipation to be hardness of stool and/ or sense of incomplete evacuation, whereas physicians may give more importance to infrequent passage of stool. In the West, bowel frequency between 3/week to 3/day is considered normal. In a panIndian study, $99 \%$ of the Indian population had stool frequency at least once a day. Among patients with IBS, median stool frequency was twice a day irrespective of whether they had a diarrhea or constipation predominant disorder. ${ }^{34}$ Only about one third of subjects with constipation had stool frequency less than 3 times a week. ${ }^{34}$ In another study from South Korea, only $27 \%$ of constipation predominant IBS subjects had Bristol stool type 1 and $2 .^{35}$ The shorter colonic transit time in the Asian population compared to the Western population is well known. ${ }^{7}$ These physiologic and socio-cultural differences may be the cause of some discordance observed in our validation study.

High sensitivity and specificity of the Bengali translated questionnaire to detect the FGIDs diagnosed clinically based on Rome III criteria is strikingly similar to the results of translation-validation study of EAR3Q in Hindi, Telugu, and Chinese languages. ${ }^{14}$ But our findings are different from the translation-validation study in
Korean, Indonesian, and Thai languages, in which the sensitivity varied between $30 \%$ and $93 \%$, and the specificity between $90 \%$ and $93 \% .{ }^{14}$ In the test-retest reliability assessment, excellent agreement in the present study is also similar to the Hindi, Telugu, and Chinese translation-validation study. ${ }^{14}$

Culture may influence the beliefs and perception about health and disease, symptoms expression, and illness behavior including the assumption of sick role. ${ }^{9-11}$ We believe that the culturally adapted, translated, and validated Bengali questionnaire has wide applicability. For example, this questionnaire may be useful for cross-cultural, multi-national epidemiologic, therapeutic and pathophysiological studies. The importance of multi-national crosscultural research has been increasingly recognized in the recent years. ${ }^{9-11}$ Moreover, physicians can use this questionnaire in clinical practice. This will help them to recognize overlap conditions that may have important implications in treatment and prognosis. ${ }^{7}$ More importantly, using this validated questionnaire in clinical practice may avoid unnecessary investigations in many patients. Thus, this questionnaire has potential application in health care practice considering the high burden of FGIDs in clinical practice and community.

One of the limitations of our study is that the questionnaire was applied in selected, educated subjects. There are minor differences in Bengali language between the West Bengal and Bangladesh; considering this, persons from both Bangladesh and West Bengal were involved during translation. This validation study was carried out in 2 urban centers. Although some of the included patients came to the capital city from different rural areas of Bangladesh, most of the included patients were from the urban and sub-urban areas. The small sample size in the validation study, particularly the number of FC patients may be a limitation. Lower sensitivity and reliability for FC compared to IBS and FD may result from the small number of FC patients in the study. Although the enrolled subjects filled up the questionnaire by themselves, a research assistant sat with the subjects while they filled in the questionnaire for any clarification, if needed. This may be a limitation, as the questionnaire is supposed to be self-administered. However, no patient needed any help. The research assistant recorded the time to complete the questionnaire. For measuring test-retest reliability, questionnaire was applied at 2-week intervals that may be short and may be prone to recall bias.

In conclusion, we successfully translated and validated the EAR3Q in Bengali. We believe that this translated questionnaire will be useful for clinical evaluation and research among the Bengali speaking population. 


\section{Supplementary Materials}

Note: To access the supplementary Table mentioned in this article, visit the online version of Journal of Neurogastroenterology and Motility at http://www.jnmjournal.org/, and at http://dx.doi. org/10.5056/jnm15129.

Acknowlegements: Authors thank Dr. Mahjuba Umme Salam from Department of Medicine of Sylhet Women's Medical College, Bangladesh for her assistance in Bengali translation. They also thank Dr. Nigar Sultana and Dr. Sayeda Rahim from Department of Gastroenterology, Shaheed Suhrawardy Medical College and Hospital, Bangladesh for their help including data collection in this translation and validation study. The authors like to thank Bangladesh Medical Research Council (www.bmrcbd.org) for funding this study. The authors also thank the Rome Foundation (http:// www.romecriteria. org), USA and Asian Neurogastroenterology and Motility Association (www.asianmotility.org) for the support. Uday C Ghoshal also thanks Shanti Public Educational and Development Society for its support.

Financial support: The authors like to thank Bangladesh Medical Research Council for funding this study.

\section{Conflicts of interest: None.}

Author contributions: M Masudur Rahman: study conceptualization, planning, supervision, data analysis, and manuscript writing; Uday C Ghoshal, study conceptualization, planning, data analysis, and manuscript writing; A H M Rowshon, Faruque Ahmed, Md Golam Kibria, Mahmud Hasan: study planning, supervision, and manuscript review; and Kok-Ann Gwee and William E Whitehead: study conceptualization, planning, and manuscript writing.

\section{References}

1. Longstreth GF, Thompson WG, Chey WD, Houghton LA, Mearin F, Spiller RC. Functional bowel disorders. Gastroenterology 2006;130: 1480-1491.

2. Drossman DA, Richter JE, Talley NJ, Corazziari E, Thompson WG, Whitehead WE. Functional gastrointestinal disorders. Boston: Little, Brown 1994.

3. Drossman DA, Corazziari E, Talley NJ, Thompson WG, Whitehead WE. Rome II: the functional gastrointestinal disorders. Diagnosis, pathophysiology and treatment: a multinational consensus. 2nd ed. VA: Degnon Associates Inc. 2000.

4. Drossman DA. Rome III: The Functional Gastrointestinal Disorders. 3rd Ed. McLean, VA: Degnon Associates Inc. 2006.

5. Moayyedi P, Ford AC. Symptom-based diagnostic criteria for irritable bowel syndrome: the more things change, the more they stay the same. Gastroenterol Clin North Am 2011;40:87-103.

6. Spiller RC, Thompson WG. Bowel disorders. Am J Gastroenterol 2010; 105:775-785.

7. Gwee KA, Lu CL, Ghoshal UC. Epidemiology of irritable bowel syndrome in Asia: something old, something new, something borrowed. J Gastroenterol Hepatol 2009;24:1601-1607.

8. Sperber AD. Translation and validation of study instruments for crosscultural research. Gastroenterology 2004;126: S124-S128.

9. Sperber AD, Gwee KA, Hungin AP, et al. Conducting multinational, cross-cultural research in the functional gastrointestinal disorders: issues and recommendations. A Rome Foundation working team report. Aliment Pharmacol Ther 2014;40:1094-1102.

10. Sperber AD. The challenge of cross-cultural, multi-national research: potential benefits in the functional gastrointestinal disorders. Neurogastroenterol Motil 2009;21:351-360.

11. Sperber AD, Drossman DA, Quigley EM. The global perspective on irritable bowel syndrome: a Rome foundation-World Gastroenterology Organisation symposium. Am J Gastroenterol 2012;107:1602-1609.

12. Tack J, Talley NJ, Camilleri M, et al. Functional gastroduodenal disorders. Gastroenterology 2006;130:1466-1479.

13. Ghoshal UC, Abraham P, Bhatia SJ, et al. Comparison of Manning, Rome I, II, and III, and Asian diagnostic criteria: report of the multicentric Indian irritable bowel syndrome (MIIBS) study. Indian J Gastroenterol 2013;32:369-375.

14. Ghoshal UC, Gwee KA, Chen M, et al. Development, translation and validation of enhanced Asian Rome III questionnaire for diagnosis of functional bowel disorders in major Asian languages: a Rome Foundation-Asian Neurogastroenterology and Motility Association Working Team Report. J Neurogastroenterol Motil 2015;21:83-92.

15. Rome III diagnostic questionnaire for the adult functional GI disorders (including alarm questions) and scoring algorithm. Available from URL: http://www.romecriteria.org/pdfs/AdultFunctGIQ.pdf (accessed 7 Mar 2016).

16. Comparative ranking of scheduled language in descending order of speaker's strength. Available from URL: http://www.censusindia.gov.in/ Census_Data_2001/Census_Data_Online/Language/Statement6.aspx (accessed 7 Mar 2016).

17. Bangla language. Available from URL: http://en.banglapedia.org/index. php?title=Bangla_Language (accessed 19 Mar 2016).

18. Masud MA, Hasan M, Khan AK. Irritable bowel syndrome in a rural community in Bangladesh: prevalence, symptoms pattern, and health care seeking behavior. Am J Gastroenterol 2001;96:1547-1552.

19. Perveen I, Hasan M, Masud MA, Bhuiyan MM, Rahman MM. Irritable bowel syndrome in a Bangladeshi urban community: prevalence and health care seeking pattern. Saudi J Gastroenterol 2009;15:239-243.

20. Perveen I, Rahman MM, Saha M, Rahman MM, Hasan M. Preva- 
lence of irritable bowel syndrome and functional dyspepsia, overlapping symptoms, and associated factors in a general population of Bangladesh. Indian J Gastroenterol 33:265-273.

21. Chang FY, Lu CL. Irritable bowel syndrome in the 21st century: perspectives from Asia or South-east Asia. J Gastroenterol Hepatol 2007;22: 4-12.

22. Ghoshal UC, Singh R, Chang FY, et al. Epidemiology of uninvestigated and functional dyspepsia in Asia: facts and fiction. J Neurogastroenterol Motil 2011;17:235-244.

23. Barzkar M, Pourhoseingholi MA, Habibi M, et al. Uninvestigated dyspepsia and its related factors in an Iranian community. Saudi Med J 2009;30:397-402.

24. Chen LY, Ho KY, Phua KH. Normal bowel habits and prevalence of functional bowel disorders in Singaporean adults - findings from a community based study in Bishan. Community medicine GI study group. Singapore Med J 2000;41:255-258.

25. Ho KY, Kang JY, Seow A. Prevalence of gastrointestinal symptoms in a multiracial Asian population, with particular reference to reflux-type symptoms. Am J Gastroenterol 1998;93:1816-1822.

26. Tan YM, Goh KL, Muhidayah R, Ooi CL, Salem O. Prevalence of irritable bowel syndrome in young adult Malaysians: a survey among medical students. J Gastroenterol Hepatol 2003;18:1412-1416.

27. Pan G, Lu S, Ke M, Han S, Guo H, Fang X. Epidemiologic study of the irritable bowel syndrome in Beijing: stratified randomized study by cluster sampling. Chin Med J 2000;113:35-39.
28. Makharia GK, VermaAK, Amarchand R, et al. Prevalence of irritable bowel syndrome: a community based study from northern India. J Neurogastroenterol Motil 2011;17:82-87.

29. Guidelines for the Translation of Rome Foundation Material. Available from URL: http://www.romecriteria.org/translations/Rome\%20Foundation\%20translation\%20guidelines.pdf (Accessed 19 Mar 2016).

30. Gururaj M. Socio-economic Status Scale-A revision of income parameter for 2014. Int J Recent Trends Sci Technol 2014;11:1-2.

31. Wang A, Liao XH, Xiong L, et al. Clinical overlap between functional dyspepsia and irritable bowel syndrome based on Rome III criteria. BMC Gastroenterology 2008;8:43.

32. Lu CL, Lang HC, Chang FY, et al. Prevalence and health/social impacts of functional dyspepsia in Taiwan: a study based on the Rome criteria questionnaire survey assisted by endoscopic exclusion among a physical check-up population. Scand J Gastroenterol 2005;40:402-411.

33. Gwee KA. Irritable bowel syndrome in developing countries--a disorder of civilization or colonization? Neurogastroenterol Motil 2005;17:317324.

34. Ghoshal UC, Abraham P, Bhatt C, et al. Epidemiological and clinical profile of irritable bowel syndrome in India; Report of the Indian Society of Gastroenterology Task Force. Indian J Gastroenterol 2008;27:22-28.

35. Park JM, Choi MG, Cho YK, et al. Functional gastrointestinal disorders diagnosed by Rome III questionnaire in Korea. J Neurogastroenterol Motil 2011;17:279-286. 